\title{
IMPROVING THE DYNAMIC PERFORMANCE OF MULTI-STOREY BUILDINGS VIA PROTECTIVE GLAZING CURTAIN WALLS
}

\author{
CHIARA BEDON \& CLAUDIO AMADIO \\ University of Trieste, Department of Engineering and Architecture, Trieste, Italy.
}

\begin{abstract}
Glazing facades are widely used in building structures, due to a series of aesthetic, thermal, lightening aspects. From a structural point of view, under the action of exceptional loads as impacts, explosions, seismic events or hazards in general, the glazing envelopes often represent the critical component for multi-storey buildings, due to the typically brittle behaviour and limited tensile resistance of the glass panes, hence requiring specific, fail-safe design concepts. In this paper, the feasibility and potential of special mechanical connectors interposed at the interface between a given multi-storey primary building structure and the glazing facade are investigated via accurate finite-element numerical models, under various impact scenarios. As shown, the final result is an assembled structural system in which the facade can work as passive control system for the primary structure, in the form of a distributed tuned-mass damper (TMD).

Keywords: blast scenarios and hazards, dissipative devices, Finite-Element numerical models, glazing curtain walls, multi-storey buildings, passive structural control, tuned-mass dampers (TMDs).
\end{abstract}

\section{INTRODUCTION AND MOTIVATION}

Glazing facades are widely used in building structures, due to a series of aesthetic, thermal, lightening aspects. In most of the cases, wide transparent surfaces are created in commercial, residential as well as strategic buildings, including airports, museums, offices, etc.

From a structural point of view, however, under the action of exceptional loads as impacts, explosions, seismic events or hazards in general, the glazing envelopes often represent a critical component for multi-storey buildings, due to the typically brittle behaviour and limited tensile resistance of glass panes, hence requiring specific, fail-safe design concepts [1]. The appropriate estimation of the vulnerability of glazing systems, as well as the prediction of their actual dynamic behaviour under exceptional loads (including the interaction between a given envelope and the substructure/primary building), or the implementation and development of advanced retrofitting and enhancing techniques, consequently, are currently open topics still requiring extended studies.

In this paper, taking advantage of major outcomes of an ongoing research investigation, the feasibility and potential of special mechanical connectors interposed at the interface between a given multi-storey primary building structure and the enclosing glazing facade are investigated via accurate finite-element (FE) numerical models, under various impact scenarios. Careful consideration is paid, in particular, for the mitigation of effects due to seismic loads and blast events. As shown, when properly designed, the proposed special connectors can markedly improve the overall dynamic performance of a given traditional structure, both in terms of global building response and local performance (i.e. at the facade components level). The final result, consequently, potentially consists in an assembled structural system in which the glazing facade can work as a passive control system for the primary structure, in the form of a distributed tuned-mass damper (TMD). 


\section{DESIGN REGULATIONS FOR GLASS FACADES UNDER EXCEPTIONAL LOADS}

The design of structural glass elements and facades in general under exceptional loads is strictly dependent on the actual performance (i.e. stiffness, resistance, etc.) of single structural components, as well as their reciprocal interaction under the assigned loading combination. As such, careful consideration should be paid also for anchoring systems, supports, framing members, etc. Glass fragments represent in fact a critical issue for people, hence cracking of panes should be generally prevented (i.e. Fig. 1(a) and (b)). On the other hand, an optimal combination of safety levels, global and local structural performances, costs should be also achieved.

As far as the given glass system to verify can be considered as a secondary component, compared to the primary structure, partial damage is generally accepted by available design standards. This is not the case of structural glass assemblies of primary importance within a given structural system. There, the glass elements or facade components should in fact able to properly resist to the incoming impulse, as well as to accommodate the overall deformations of the building as a whole, including both out-of-plane and in-plane displacements. In the latter case, it is hence clear that special mechanical connectors and fasteners are mandatory to satisfy design regulations and avoid severe damage.

General European standards for the seismic design of buildings can be applied to glass curtain walls (see, for example, Ref. [2]). There, secondary components only are considered, however, and no specific design regulations are available to account for the importance or typology the curtain wall belongs, as well as for detailing, anchoring systems, etc. More detailed provisions are included in FEMA 450 [3], even for secondary non-structural cladding systems only, where drift limit values to satisfy in order to avoid glass fallout are specified for glazed curtain walls, storefronts and partitions.

Regarding the design of blast resistant windows and facades in general, EU as well as US standards are available for testing laminated glass windows $[4,5]$, and hence to define the corresponding hazard level. The latter one, due to glass intrinsic brittleness, is typically measured by the fragments that are found after the experiment behind the glass pane (see Fig. 1(c)).

\section{EXPLORING THE DESIGN CONCEPT OF DISTRIBUTED TMD FACADES}

\subsection{Theoretical background}

The design concept of building structures equipped by vibration control devices and dissipative glazing curtain walls (GCWs) takes inspiration from the original TMD concept, as

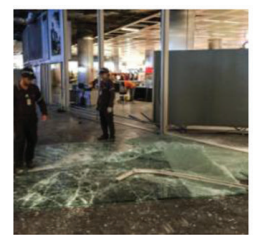

(a)

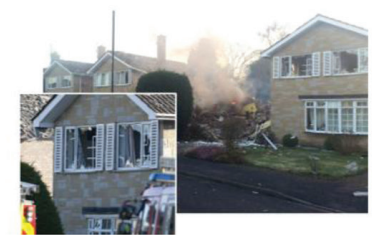

(b)

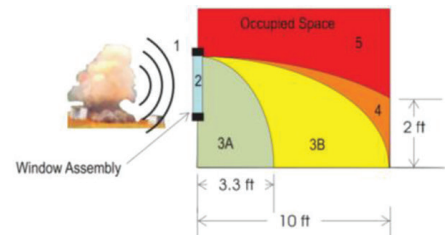

(c)

Figure 1: Glass systems under hazards. (a) and (b) Collapse examples and (c) performance chart [5]. 
well as from the use in traditional facades of special fasteners able to act as passive impact absorbers (Fig. 2).

The use of vibration control systems in facades for the enhancement of tall buildings performance under wind and seismic loads has been first theoretically explored in Ref. [6], with attention for double skin (DS) facades. There, DS facades with special connectors proved to reduce the seismic effects on tall buildings (up to -35\%). Further applications of special connectors have been proposed for cable supported facades under explosions [7, 8], while special viscoelastic (VE) or ADAS brackets for GCWs have been numerically investigated in Ref. [9], giving evidence of their potential. In this paper, the design concept of GCWs acting as passive absorbers for buildings under several hazard typologies is further investigated, via computationally efficient but accurate FE models.

The dynamic performance of a building with GCW and vibration control devices can be generally described as shown in Fig. 2 (detail box). The primary structure (total mass $M_{\text {struct }}$, stiffness $K_{\text {struct }}$, damping $c_{\text {struct }}$ ) interacts with the GCW - namely representative of additional mass $M_{\text {glass,tot }}$ but limited stiffness, for the primary structure - via special connectors replacing the usually rigid brackets ( $K_{d, t o t}$ and $c_{d, t o t}$ their total stiffness and damping). The dynamic behaviour of such a SDOF-TMD under a given design load, in particular, is described by [6]:

$$
\begin{gathered}
M_{\text {struct }} \ddot{u}(t)+C_{\text {struct }} \dot{u}(t)+K_{\text {struct }} u(t)=P(t)+C_{d, \text { tot }} \dot{u}_{d}(t)+K_{d, t o t} u_{d}(t) \\
M_{\text {glass }, \text { tot }} \ddot{u}_{d}(t)+C_{d, \text { tot }}\left(\dot{u}_{d}(t)-\dot{u}(t)\right)+K_{d, \text { tot }}\left(u_{d}(t)-u(t)\right)=p(t)
\end{gathered}
$$

where $u(t)$ is the deflection in time of the primary structure; $u_{d}(t)$ denotes the GCW relative displacement; $P(t)$ and $p(t)$ represent the force acting on the building mass or on the TMD mass, respectively.

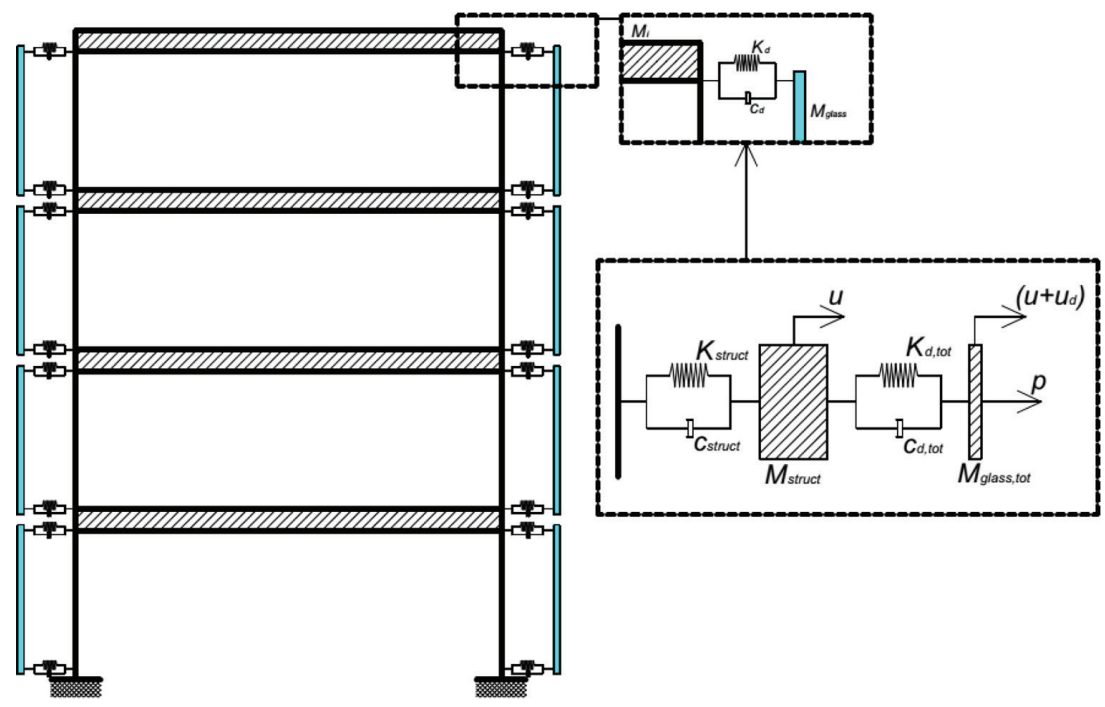

Figure 2: Reference mechanical model for the analysis of a building with dissipative GCW. 


\subsection{Design considerations and prototype}

Assuming that the single GCW modular unit is connected to the adjacent primary frame by means of four fasteners (i.e. one device at each panel corner), the preliminary estimation of $K_{d, t o t}$ and $c_{d, t o t}$ can be carried out based on Fig. 3. There, $M_{\text {glass }}$ is the total mass of a single GCW panel (plus the supporting frame), while $K_{d}$ and $c_{d}$ denote the stiffness and damping terms for a single device.

The typical control system can be composed by a VE solid damper, consisting of metal plates and a middle rubber layer ( $h_{d}$ its thickness and $A_{d}$ the surface area). The device base is directly attached to the structural backup (e.g. concrete slab) by means of anchoring bolts, whereas a further sliding steel plate supports the GCW framing members, enabling possible crushing and rotations of the VE layer. To this aim, at the interface between the VE compound and the sliding steel bracket, additional gaskets are interposed, so to avoid direct contact and infinitely rigid restraints for the sliding VE layer.

The prototype of Fig. 3 takes inspiration from classical viscous dampers in use for the seismic mitigation of tall buildings, see Ref. [10]. For design purposes, key parameters under well-defined loading conditions (e.g. operating frequency $\omega$ and temperature $T$ ) are the damping ratio $c_{d}$ deriving from the rubber compound and the corresponding stiffness $K_{d}$, where [10]:

$$
c_{d}=c_{d}(\omega)=\frac{K^{\prime \prime}}{\omega}=\eta \frac{K^{\prime}}{\omega},
$$

with $\eta$ the loss factor of the VE layer and

$$
K^{\prime}=\frac{G^{\prime}(\omega) A_{d}}{h_{d}}, K^{\prime \prime}=\frac{G^{\prime \prime}(\omega) A_{d}}{h_{d}}
$$

the storage and loss stiffnesses, where $G^{\prime}(\omega)$ and $G^{\prime \prime}(\omega)$ denote the corresponding shear moduli.

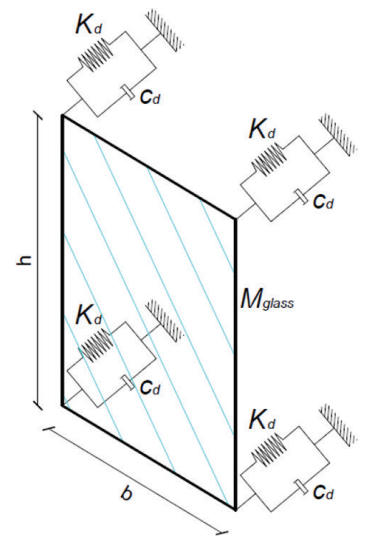

(a)

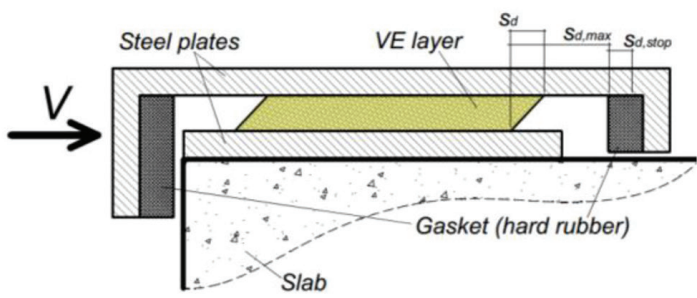

(b)

Figure 3: GCW with vibration control devices. (a) Reference mechanical model and (b) example of VE solid damper, with evidence of its working mechanism (cross-section). 
Assuming a high damping rubber compound $(\xi=20 \%)$, an average value $G^{\prime}=0.35 \mathrm{MPa}$ was taken into account $[11,12]$. In terms of gaskets, conversely, an hard compound was considered $\left(G^{\prime}=1.2 \mathrm{MPa}\right)$, with damping contributions fully neglected. Given the fundamental period $T_{1}$ of the primary structure, a preliminary estimation of $K_{d}$ can be rationally carried out as:

$$
K_{d}=\frac{1}{4} K_{d, \text { glass }}=\frac{M_{\text {glass }} \pi^{2}}{T_{1, \text { glass }}^{2}}
$$

with $T_{1, \text { glass }}=T_{1}$, which is by equaling the vibration period of the GCW modular unit and the building one. The corresponding damping term is then given by [13]:

$$
c_{d}=\frac{1}{4} c_{d, \text { glass }}=\frac{1}{4}\left(\xi \cdot c_{c r}\right)=\frac{1}{4}\left(\xi \cdot 2 M_{\text {glass }} \omega_{1, \text { glass }}\right),
$$

with $w_{l, \text { glass }}$ being assumed to coincide with the damper operating frequency, $\xi$ the VE damping coefficient and $c_{c r}$ its critical value.

Finally, see Fig. 3, possible failure mechanisms in the VE layer (i.e. tearing) under a given design load should be properly prevented, by limiting its maximum shear deformations:

$$
s_{d} \leq s_{d, \max }=\min \left(2 h_{d} ; 30\right) \text { in }[\mathrm{mm}] .
$$

\section{FINITE-ELEMENT NUMERICAL INVESTIGATION}

\subsection{FE modelling approach and solving strategy}

In this paper, the feasibility and potential of the proposed VE connectors is assessed via FE numerical simulations. Compared to earlier research efforts, careful consideration is given to a given GCW module under the effects of various types of impact loads, including blast events, as well as seismic loads. To this aim, simulations are carried out at the level of a full 3D building, as well as in terms of single GCW components, so to explore global and local effects.

Beside the source and features of the input load, in any case, the same general FE modelling approach was taken into account and the typical FE model was assembled and calibrated so to represent a traditional GCW modular unit.

In order to maximize the computational efficiency of FE models but preserve their accuracy, the GCW unit was numerically described in the form of shell elements, beam elements and mechanical joints, see Fig. 4. A total number of 6000 elements was used to represent the glass pane and the supporting frame, with 35000 DOFs. For the glass panel, 4-node and 3-node monolithic shell elements (S43, S3R) were defined, with a total thickness of $24 \mathrm{~mm}$ [9]. Based on a free meshing technique, the size of shell elements was refined in the central region of the pane (i.e. where cracks are expected) and optimized towards the edges, see Fig. 4(b), with average length comprised between $0.004 \mathrm{~m}$ and $0.1 \mathrm{~m}$. The metal frame was described via 1D beam elements (B31 type), with box cross-sectional shape well representative of a typical framing system for GCWs [9]. In the latter case, the mesh size was set to $0.1 \mathrm{~m}$, so to have an optimal correspondence between mesh nodes lying on the glass panel edges and along the frame members. 


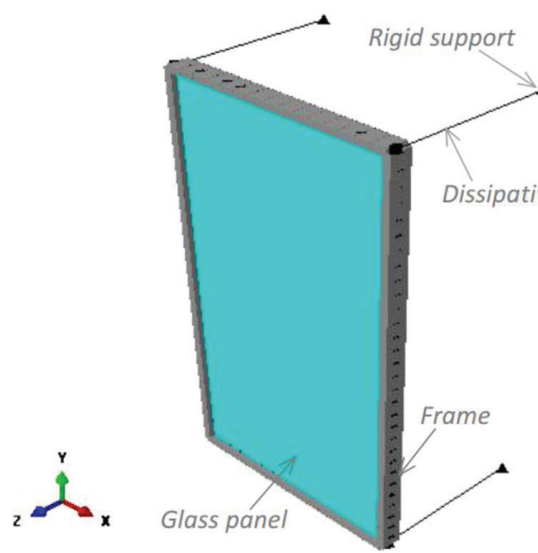

(a)

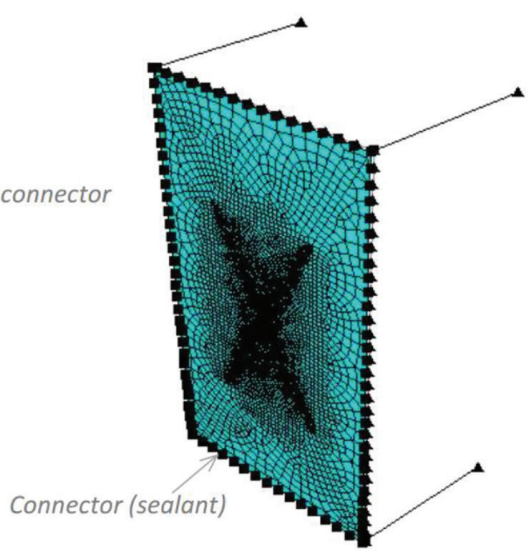

(b)

Figure 4: FE model assembly and features. (a) Extruded view and (b) overview of mesh patterns and mechanical connectors (ABAQUS [14]).

A key role was then assigned to joints, being representative of the actual mechanical interaction between the glass panel and the frame (where sealant joints and gaskets are usually interposed between them), as well as of the structural behaviour of proposed VE fasteners.

In the first case, a combined 'cartesian + rotation' joint was assigned to all the glass panel/ frame nodes. Aiming to take into account metal gaskets and frame detailing, relative rotations were restrained between the involved nodes, while a brittle elastic behaviour was defined to represent the in-plane stiffness of sealant joints [9].

To reproduce the mechanical response of VE connectors, nonlinear joints ('cylindrical' type of ABAQUS library [14]) were indeed linked to the frame corner nodes, see Fig. 4. Stiffness and damping properties for the VE compound were estimated by taking into account eqns (6) and (7). The presence of hard rubber gaskets was also properly considered.

In terms of materials, the brittle cracking damage model was used for glass, so to take into account possible tensile cracking of the panel. Input parameters were calibrated in accordance with Ref. [9]; with $85 \mathrm{MPa}$, the reference tensile resistance of annealed float glass under impulsive loads and $E_{g}=70 \mathrm{GPa}$ the modulus of elasticity. An elasto-plastic constitutive law was indeed then defined for the metal frame, with $E_{a}=70 \mathrm{GPa}, s_{y, a}=200 \mathrm{MPa}, s_{u, a}=280 \mathrm{MPa}$ the nominal reference values for Young modulus and yielding/ultimate stresses [9].

\subsection{Seismic loads}

The potential of GCWs with VE fasteners in presence of seismic loads was first considered, by taking into account a full 3D system, being representative of a steel framed, 3-storey building, see Fig. 5(a).

To this aim, the typical GCW unit shown in Fig. 4 was reproduced in series, to describe a full facade (see details of Fig. 5), and properly restrained to the steel frame. Nonlinear dynamic simulations were then carried out by imposing a set of seven seismic records at the building base. All the records, consisting of two-component acceleration data, were derived to be consistent with an EC8 [2] acceleration spectrum associated to type A soil (rock soil), T1 topographic category, $0.35 \mathrm{~g}$ peak ground acceleration and 50 years of nominal life (ultimate limit state). 


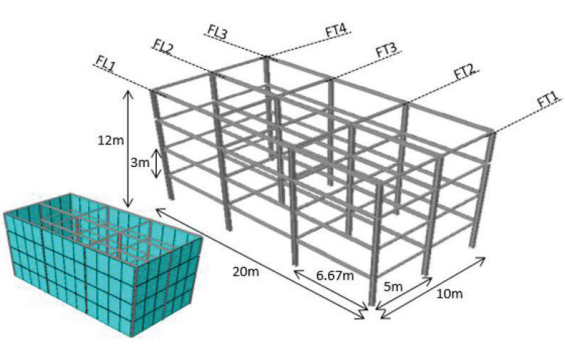

(a)

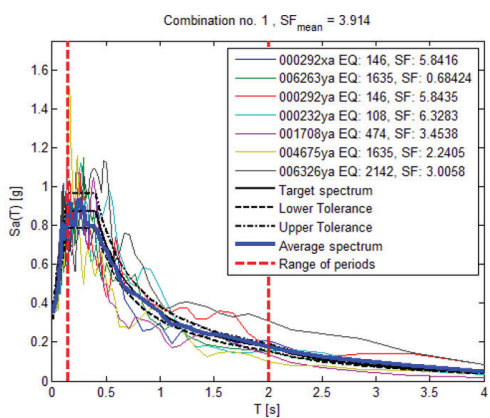

(b)

Figure 5: (a) Full 3D steel building (ABAQUS [14]) and (b) set of seismic acceleration spectra.

Following section $3, K_{d}$ was first estimated as a function of the building period $T_{1}=0.326 \mathrm{~s}$, as numerically calculated. A non-dimensional magnifying coefficient $R_{K}$ was then also defined, so that the actual stiffness of a single VE device could be calculated - through the FE parametric study - as (with $1 \leq R_{K} \leq 50$, in this study):

$$
K_{d}=\left(\frac{M_{\text {glass }} \pi^{2}}{T_{1}^{2}}\right) \cdot R_{K}
$$

Figure 6 summarizes the typical effect of the proposed VE devices, for the examined building under seismic events. As far as $K_{d}$ modifies, in accordance with eqn (9), a certain flexibility and damping capacity is progressively introduced in the traditional frame with fully rigid brackets (i.e. $R_{K} \geq 50$ ).

In terms of global performance of the building, beside the assigned $R_{K}$ value, the fundamental vibration shape was found to slightly modify, see Fig. 6(a). At the same time, limited variations were observed in terms of fundamental period $T_{1}$. However, due to the additional flexibility and damping terms deriving from VE fasteners, major benefits were indeed noticed in terms of mitigation of seismic effects on the main building as well as on glass panels.

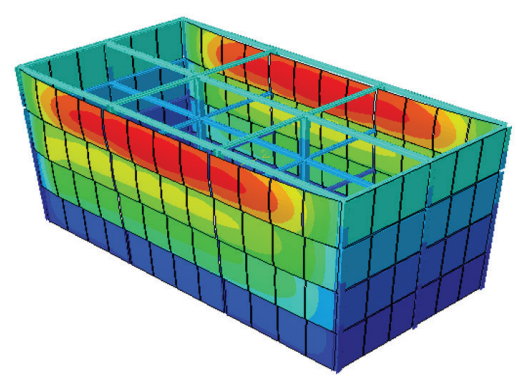

(a)

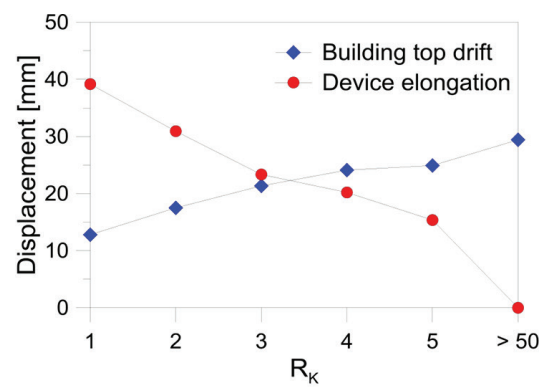

(b)

Figure 6: Seismic performance a 3D building with GCWs and VE devices (ABAQUS [14]). (a) Fundamental vibration shape and (b) top drift/ VE device elongation, by varying $K_{d}$. 
In Fig. 6(b), for example, maximum top drift amplitudes measured for the full 3D frame under the assigned set of seismic accelerations are proposed, for some selected FE models, and compared with the corresponding elongation of VE devices. As shown, a $R_{K} \geq 50$ coefficient was found to coincide with almost fully rigid brackets for the GCW, hence the benefits of VE fasteners expected to vanish. As far as $R_{K}$ decreases, the combination of additional flexibility and damping capacity due to VE connectors manifests in a marked reduction of the measured building top drift, with progressively increasing sliding demand for the VE devices. In this regard, based also on design concepts summarized in section 3, parametric FE studies partly discussed in this paper proved to offer - for the examined case study - maximum benefits of VE devices for $R_{K}$ values equal to $\approx 3-5$.

In terms of dynamic response of the single GCW module and VE effects on the unit components, further comparative FE results are proposed in Fig. 7, with evidence of tensile stresses amount and distribution in glass under the assigned set of ground accelerations. Due to combined flexibility and damping properties of VE devices (when properly designed), part of the incoming seismic input energy is preliminary dissipated. As a result, the single GCW unit as well as the bare frame supporting the facade are subjected to a reduced impulse, compared to the same 3D system with fully rigid brackets.

In this sense, maximum peaks of stresses in glass are first highly mitigated by VE devices (see Fig. 7(a)). At the same time, the additional flexibility of GCW supports also beneficially affects the overall distribution of maximum stresses in the glass panels. As shown in Fig. 7(b) and (c), local peaks of stresses close to the glass supports and edges of glass can be generally avoided, thanks to VE fasteners, with obvious benefits for the overall dynamic performance of the full structural system.

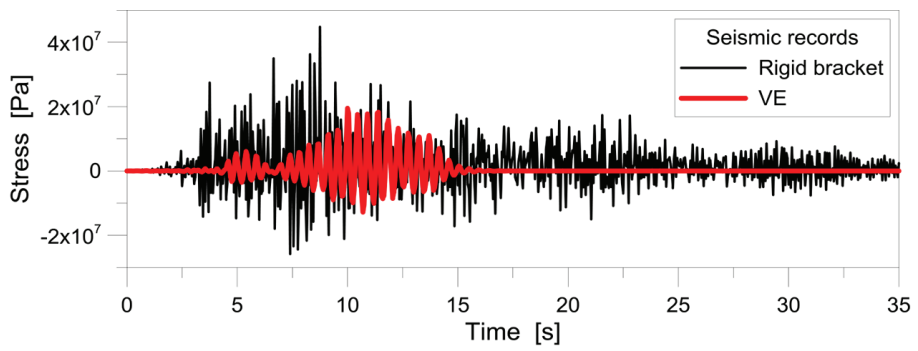

(a)

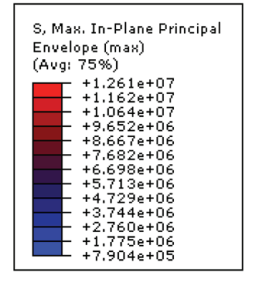

(b) Rigid bracket

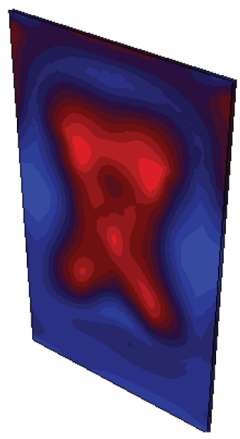

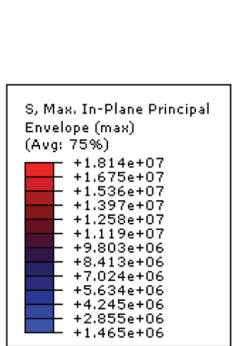

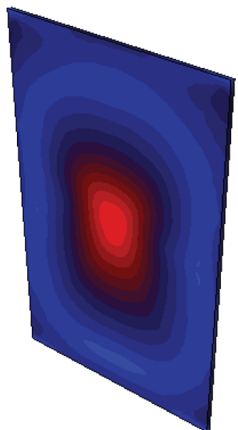

(c) $\operatorname{VE}\left(R_{K}=4\right)$

Figure 7: Tensile stresses in glass for the GCW unit under seismic events (ABAQUS [14]). (a) Maximum envelope (panel center) and (b)-(c) contour plot $(t=10 \mathrm{~s}$, with legend in $\mathrm{Pa}$ ). 


\subsection{Blast loads}

By taking into account the same GCW unit of Fig. 4, its dynamic response under blast pressures was then also investigated, in order to further assess the potential of proposed VE devices.

Based on section 4.2, the $R_{K}=4$ configuration was first taken into account, since representative of a rather optimal balance of hazard mitigation and VE device performances for the case study building under seismic events.

In particular, several input blast waves were taken into account by considering a certain amount of equivalent TNT charge and a given stand-off distance of $30 \mathrm{~m}$ from the facade.

Both the positive and negative phases were considered, in accordance with [9]. The so defined blast pressure waves were then applied on the glass surface in the form of uniform, time-varying pressures. In Fig. 8, major outcomes of selected FE simulations are proposed.

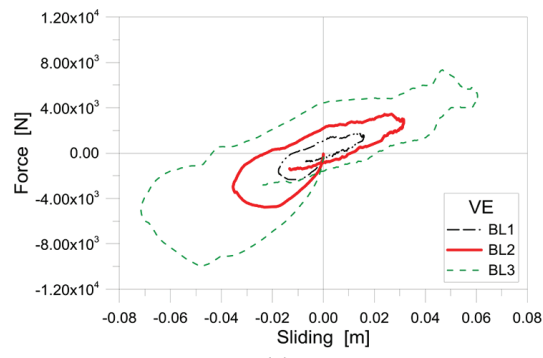

(a)

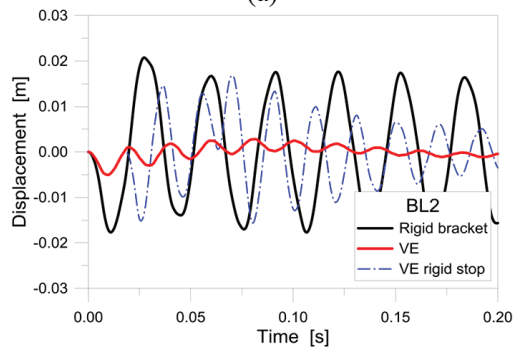

(c)
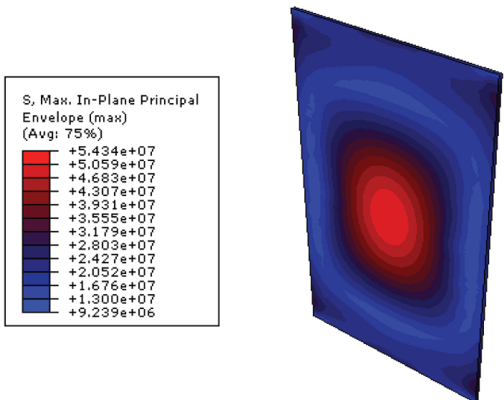

(e) Rigid bracket $(t=0.01 \mathrm{~s}, \mathrm{BL} 2)$

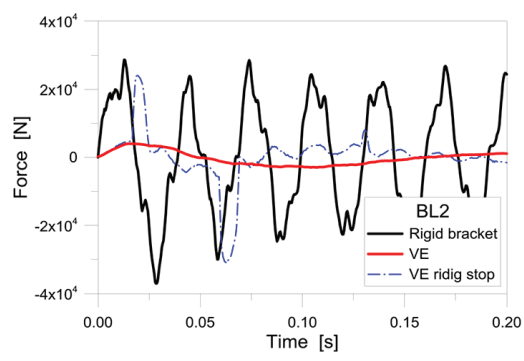

(b)

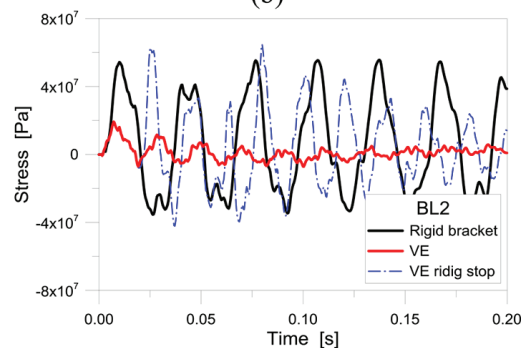

(d)
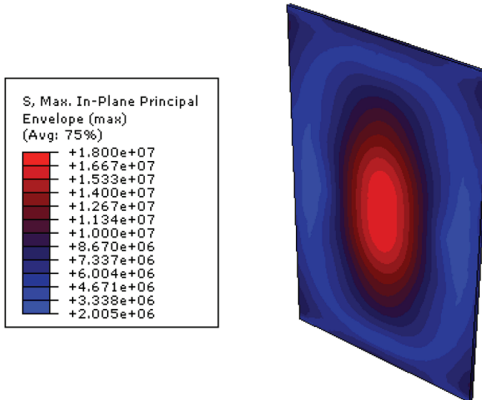

(f) $\operatorname{VE}\left(R_{K}=4, t=0.007 \mathrm{~s}, \mathrm{BL} 2\right)$

Figure 8: Response of the GCW unit under blast loads (ABAQUS [14]), with FE results proposed for the $R_{K}=4$ configuration. (a) VE connector behaviour; (b) reaction forces at the supports, as a function of time; (c) relative displacements and (d) maximum stresses at the center of glass. (e)-(f) Blue-to-red contour plot of tensile stresses in glass (legend in $\mathrm{Pa}$ ). 
There, the loading configurations denoted as BL1, BL2 and BL3 correspond, respectively, to a charge of $12.5 \mathrm{Kg}, 25 \mathrm{Kg}$ and $50 \mathrm{Kg}$ of explosive, being representative of blast loads B (low level), C (medium) and D (high), as defined by design standards [5].

As shown in Fig. 8(a), rather stable behaviour was generally observed for the VE devices, even under impulsive blast waves typically characterized by abrupt release of energy and limited duration, in the order of thousand of milliseconds. Under the BL2 loading configuration, in particular, it can be seen in Fig. 8(b) to (d) that the actual effects of the incoming blast pressure are again markedly reduced, compared to the traditional GCW restrained by means of rigid brackets. In accordance with Fig. 8(b), moreover, maximum reaction forces monitored at the GCW corners are in the order of $\approx 5 \mathrm{kN}$ for the unit with VE fasteners, compared to $\approx 38 \mathrm{kN}$ for the module with rigid brackets, with marked benefits for the primary structure. In Figs 8(e)-(f) the distribution of tensile stresses is finally also compared, for the GCW panel with rigid supports or VE fasteners. Worth of interest, in the same figures, is the effect of hard rubber gaskets interposed between the VE compound and the steel bracket (i.e. cross-section of Fig. 3). As far as an infinitely rigid stop is considered only for the deformed VE layer, in fact, an abrupt increase of measured reaction forces at the supports, as well as maximum deflections and stresses in glass can be observed. The same fully rigid stops, in particular, would involve an additional impulse for the sliding GCW unit. As a result, the potential benefits of the same VE fasteners could fully vanish, with a dynamic performance of the GCW panels rather in close correlation with the traditional modules.

\section{CONCLUSIONS}

In this paper, the feasibility and potential of special mechanical joints interposed at the interface between a given multi-storey primary building and a traditional glazing curtain wall have been investigated via accurate finite-element (FE) numerical models, under various impact scenarios. Careful consideration has been paid for seismic events as well as blast loads, being representative of exceptional and high rise loading conditions for facades and buildings. Based on properly designed fasteners able to introduce additional flexibility and damping capacities in the traditional building, the maximum effects and benefits of such connectors have been emphasized, both in terms of global performance as well as local and component behaviour for the case study object of investigation, giving evidence of the potential of GCWs acting as distributed tuned mass dampers (TMDs) for multi-storey buildings under hazards.

\section{ACKNOWLEDGEMENTS}

Part of this research study has been financially supported within the FRA2016 'Inverse' project ('Università degli Studi di Trieste - Finanziamento di Ateneo per progetti di ricerca scientifica - FRA2016'). 'Fondazione CaRiGo' is also acknowledged for providing financial support.

\section{REFERENCES}

[1] Larcher, M., Arrigoni, M., Bedon, C., Van Doormaal, A., Haberacker, C., Hüsken, G., Millon, O., Saarenheimo, A., Solomos, G., Thamie, L., Valsamos, G., Williams, A. \& Stolz, A., Design of blast-loaded glazing windows and facades: a review of essential requirements towards standardization. Advances in Civil Engineering, 2016, Article ID. 2604232, pp. 14, 2016.

https://doi.org/10.1155/2016/2604232 
[2] EN 1998-1-1. Eurocode 8 - Design of structures for earthquake resistance - Part 1: General rules, seismic actions and rules for buildings. CEN, Brussels, Belgium, 2004.

[3] FEMA 450. Recommended provisions for seismic regulations for new buildings and other structures, 2003.

[4] ISO 16933:2007/Cor1:2008, Glass in building - Explosion-resistant security glazing Test and classification for arena air-blast loading, 2008.

[5] GSA-TS01. Standard test method for glazing and window systems subject to dynamic overpressure loadings. US General Services Administration, 2003.

[6] Moon, K.S., Vertically distributed multiple tuned mass dampers in tall buildings: performance analysis and preliminary design. The Structural Design of Tall and Special Buildings, 19, pp. 347-366, 2010.

https://doi.org/10.1002/tal.499

[7] Bedon, C. \& Amadio, C., Exploratory numerical analysis of two-way straight cable-net facades subjected to air blast loads. Engineering Structures, 79, pp. 276-289, 2014. https://doi.org/10.1016/j.engstruct.2014.08.023

[8] Amadio, C. \& Bedon, C., Viscoelastic spider connectors for the mitigation of cablesupported facades subjected to air blast loading. Engineering Structures, 42, pp. 190-200, 2012.

https://doi.org/10.1016/j.engstruct.2012.04.023

[9] Bedon, C. \& Amadio, C., Passive control systems for the blast enhancement of glazing curtain walls under explosive loads. The Open Civil Engineering Journal, 10, pp. 3-26, 2016.

[10] Park, S.W., Analytical modeling of viscoelastic dampers for structural and vibration control. International Journal of Solids and Structures, 38(44-45), pp. 8065-8092, 2000.

[11] Xiaoming, C., Jin, D. \& Yungui, L., Mass proportional damping in nonlinear timehistory analysis. Proceeding of 3rd IC3ME2015, June 27-28, Guangzhou, China, 2015.

[12] Alipour, A. \& Zareian, F., Study Rayleigh damping in structures - Uncertainties and treatments. Proceedings 14th WCEE, October 12-17, Beijing, China, 2008.

[13] Chopra, A.K., Dynamics of Structures - Theory and Applications to Earthquake Engineering, 4th ed., Prentice Hall, Upper Saddle River, New Jersey, 2011.

[14] Systèmes Dassault. ABAQUS v. 6.12, Providence, RI, 2013.

[15] Bedon, C., Amadio, C. \& Sinico, A., Numerical and analytical investigation on the dynamic buckling behavior of glass columns under blast. Engineering Structures, 79, pp. 322-340, 2014.

https://doi.org/10.1016/j.engstruct.2014.08.024 